\title{
Penerapan Progressive Web Application (PWA) pada E-Commerce
}

\author{
Implementation of Progressive Web Application (PWA) on E-Commerce
}

\author{
Nurwanto \\ Program Studi Teknik Informatika, Fakultas Teknik, Universitas Muhammadiyah Ponorogo \\ Jl. Budi Utomo No.10, Ponorogo, Telp: (0352) 481124 \\ E-mail: noeng.hunter@gmail.com
}

\begin{abstract}
Abstrak
Strategi mobile development dibagi dalam dua kelompok utama yaitu native development dan web-base development. Aplikasi native mobile dikembangkan hanya pada satu platform dan menggunakan bahasa pemrograman dan tools dari platform itu sendiri, tetapi memiliki kinerja tinggi dan User Experience (UX) yang baik. Sebaliknya, web-base development yang menggunakan teknologi web, seperti HTML5, CSS, dan JavaScript untuk mengembangkan aplikasi mobile yang dapat digunakan di platform apa pun. Teknologi terbaru dari web-base application adalah Progressive Web Apps (PWA). PWA adalah teknologi yang dirancang untuk mengatasi keterbatasan browser seluler dan aplikasi native. PWA menggunakan kemampuan web modern yang menggambarkan koleksi teknologi, konsep desain, dan API Web yang bekerja bersama-sama untuk menghadirkan pengalaman pengguna seperti aplikasi native. PWA dapat dijalankan dengan mengklik ikon di layar utama ponsel sama seperti bagaimana seseorang menggunakan aplikasi native. PWA dapat langsung dijalanlan walaupun tidak ada jaringan internet serta mendukung splash screen dan push notification. Tujuan dari penelitian ini adalah menerapkan PWA pada web e-commerce agar dapat dijalankan melalui ponsel tanpa harus membuat ulang kode program dengan menggunakan bahasa pemrograman Java dan SDK. Hasil dari penelitian yang dilakukan yaitu dengan merapkan PWA pada ecommerce pengguna dapat menjalankan aplikasi e-commerce layaknya aplikasi native yang dapat dijalankan dengan mengklik ikon pada layar utama ponsel. E-commerce juga dapat diakses pada berbagai platform dengan menggunakan browser seluler maupun desktop dengan adanya jaringan internet maupun offline. Pengujian yang dilakukan berdasarkan baseline progressive web app checklist, nilai kualitas PWA pada e-commerce cukup baik yaitu 93,75 dari 100 nilai maksimal. Dari 16 kriteria pengujian, 15 diantaranya dapat diimpelementasikan pada e-commerce.
\end{abstract}

Kata kunci: E-commerce, Native Development, PWA, Web-Based Application

\begin{abstract}
Mobile development strategy consists of two main categories, namely native development and web-base development. Native mobile application is merely developed into one platform. It uses programming language and tools from the platform itself. However, it has high performance and good User Experience (UX). Conversely, web-base development using web technologies such as HTML5, CSS, and JavaScript, for developing mobile application that can be used in any platforms. The recent technology of web-base development is Progressive Web Application (PWA). It is a technology designed for coping with limitation of cellular browser and native application. It applies modern web capability illustrating the collection of technology, design concept, and API Web working together for presenting user experience like native application. It can be run by clicking icon in cellphone home screen likewise how someone using native application. It is able to be run, even though there is no internet access. It
\end{abstract}


also supports splash screen and push notification. This study aims to implement PWA on ecommerce web in order to be able to be run via cellphone without rebuilding program code by applying Java and SDK programming languanges. Result of this study was conducted by implementing PWA on user's e-commerce that can run e-commerce application like native application did by clicking icon in cellphone home screen. E-commerce is also able to be accessed in any platforms by using cellular browser and desktop as well as with or without internet access. Based on the progressive web app checklist, the quality value of PWA on ecommerce is quite good, 93.75 out of 100 maximum values. Of the 16 testing criteria, 15 of which can be implemented on e-commerce.

Keywords: E-commerce, Native Development, PWA, Web-Based Application

\section{PENDAHULUAN}

Saat ini, dunia bergerak menuju aplikasi mobile dan total aktivitas pada ponsel melalui penjelajahan web atau melalui aplikasi native hampir mendekati $67 \%$ yang diidentifikasi oleh survei baru-baru ini. Sebagian besar pengguna menghabiskan waktunya untuk menelusuri situs melalui web browser pada ponsel. Tetapi karena antarmuka sebagian besar situs web tidak otomatis responsif di web browser seluler menyebabkan pengguna tidak merasa senang sehingga dibutuhkan teknologi yang dapat mengatasi masalah tersebut [1].

Dengan pesatnya teknologi mobile saat ini, strategi mobile development dibagi dalam dua kelompok utama yaitu native development dan web-base development. Aplikasi native mobile dikembangkan hanya pada satu platform dan menggunakan bahasa pemrograman dan tools dari platform itu sendiri, misalnya, aplikasi native Android dikembangkan dengan menggunakan bahasa pemrograman Java dan Android Software Development Kit (SDK). Aplikasi native memiliki kinerja tinggi dan User Experience (UX) yang baik [2]. Namun, karena kode program dari platform tersebut tidak dapat digunakan kembali di platform lain maka diperlukan pengembangan dan membuat ulang kode program agar dapat digunakan pada platform lain sehingga biaya perawatan yang dibutuhkan lebih tinggi [3]. Sebaliknya, web-base development yang menggunakan teknologi web, seperti HTML5, CSS, dan JavaScript untuk mengembangkan aplikasi mobile yang dapat digunakan di platform apa pun dapat mengatasi masalah tersebut [4][5].

Progressive Web Apps (PWA) adalah teknologi yang dirancang dan dikembangkan oleh Google pada Juni 2015 untuk mengatasi keterbatasan browser seluler dan aplikasi native. PWA menggunakan kemampuan web modern yang menggambarkan koleksi teknologi, konsep desain, dan API Web yang bekerja bersama-sama untuk menghadirkan pengalaman pengguna seperti aplikasi native [6]. PWA dapat dijalankan dengan mengklik ikon di layar utama ponsel sama seperti bagaimana seseorang menggunakan aplikasi native. PWA dapat langsung dijalanlan walaupun tidak ada jaringan internet serta mendukung splash screen dan push notification [1]. Tujuan dari penelitian ini adalah menerapkan PWA pada web e-commerce agar dapat dijalankan melalui ponsel tanpa harus membuat ulang kode program dengan menggunakan bahasa pemrograman Java dan SDK. Selain itu, e-commerce dapat diakses apabila pengguna mempunyai jaringan internet yang buruk dan dapat berjalan pada kondisi offline.

\section{METODE PENELITIAN}

\subsection{Metode Perancangan Perangkat Lunak}

Metode perancangan perangkat lunak yang digunakan pada penelitian ini menggunakan model prototype dengan 3 tahapan yang dapat dilihat pada gambar 1. 


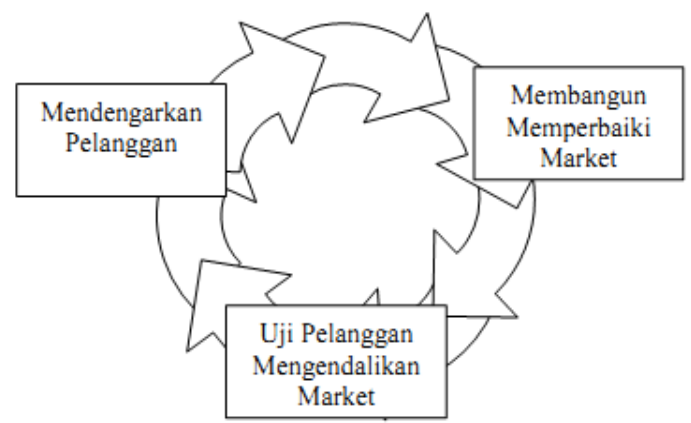

Gambar 1 Model Prototype [7]

Tahap pertama dari model prototype yaitu mendengarkan pelanggan, pada tahapan ini pelanggan menginginkan sebuah halaman web khususnya e-commerce dapat juga dijalankan dalam bentuk aplikasi mobile yaitu Android tanpa harus membuat ulang kode program yang sudah ada. Tahap kedua yaitu membangun dan memperbaiki prototype, pada tahapan ini dilakukan perancangan dan pengkodean e-commerce sesuai keinginan pelanggan dengan menggunakan CMS (Content Management System) Wordpress. Tahap ketiga yaitu pengujian prototype, pada tahapan ini pengujian dilakukan dengan mengakses e-commerce melalui smartphone untuk mengetahui fungsionalitasnya apakah sudah sesuai keinginan pelanggan, serta menguji penerapan Progressive Web Apps (PWA).

2.2. Rancangan Aplikasi

Arsitektur PWA pada e-commerce terdiri dari 3 bagian yaitu web app manifest, app shell, dan service worker.

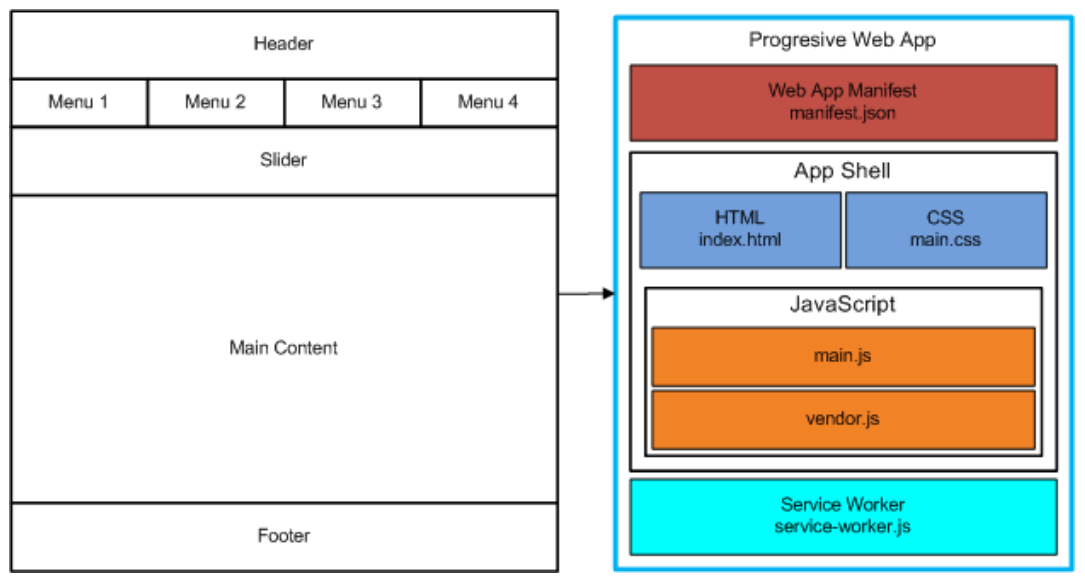

Gambar 2 Arsitektur PWA pada E-commerce

Bagian pertama yaitu manifest.json digunakan untuk menyimpan konfigurasi aplikasi PWA diantaranya yaitu nama aplikasi, deskripsi, ikon, background color, theme color dan orientation. Selain itu, dengan manifest.json dapat memunculkan pop-up "tambahkan ke layar utama" pada browser. Bagian kedua yaitu app shell yang terdiri dari HTML, CSS, JavaScript dan sumber daya lainnya yang menyediakan struktur untuk halaman e-commerce. Bagian ketiga yaitu service worker yang memungkinkan e-commerce dapat diakses secara offline.

\subsection{Rancangan Pengujian Aplikasi}

Kriteria pengujian berdasarkan baseline progressive web app checklist yang dilakukan dengan menggunakan 2 cara yaitu menggunakan tools Lighthouse dan pengujian manual. Lighthouse merupakan sebagai alat bantu yang digunakan untuk audit atau pengujian untuk meningkatkan kualitas aplikasi web yang bisa dijalankan sebagai ekstensi Chrome. Beberapa pengujian aplikasi web yang dapat dilakukan dengan menggunakan Lighthouse diantaranya 
yaitu Performance, Accessibility, Best Practices, SEO dan PWA. Pengujian PWA dengan Lighthouse terdiri dari 13 kriteria dan 3 kriteria lainnya dilakukan secara manual, sehingga total pengujian yaitu 16 kriteria setiap kriteria memiliki nilai 6,25 dengan nilai total 100.

\section{HASIL DAN PEMBAHASAN}

Pada penelitian ini dibagi menjadi 3 bahasan yaitu impementasi e-commerce dengan menggunakan CMS (Content Management System) Wordpress, menerapkan PWA dan menguji PWA berdasarkan baseline progressive web app checklist.

3.1. Implementasi E-Commerce

Pada penelitian ini penulis menggunakan CMS (Content Management System) Wordpress dengan theme Metro Store dan plugins Woocommerce untuk membuat e-commerce. Beberapa plugins yang perlu ditambahkan yaitu Jetpack by WordPress.com, Regenerate Thumnails, YITH WooCommerce Quick View, YITH WooCommerce Compare dan YITH WooCommerce Wishlist. Theme Metro Store merupakan salah satu responsive theme yang dikhususnya untuk membangun web e-commerce yang otomatis responsif. Untuk mengimplementasikan PWA pada e-commerce langkah pertama adalah membuat web $e$ commerce terlebih dahulu. Secara umum tampilan e-commerce yang sudah dibuat dapat dilihat pada gambar 3 dan gambar 4 .

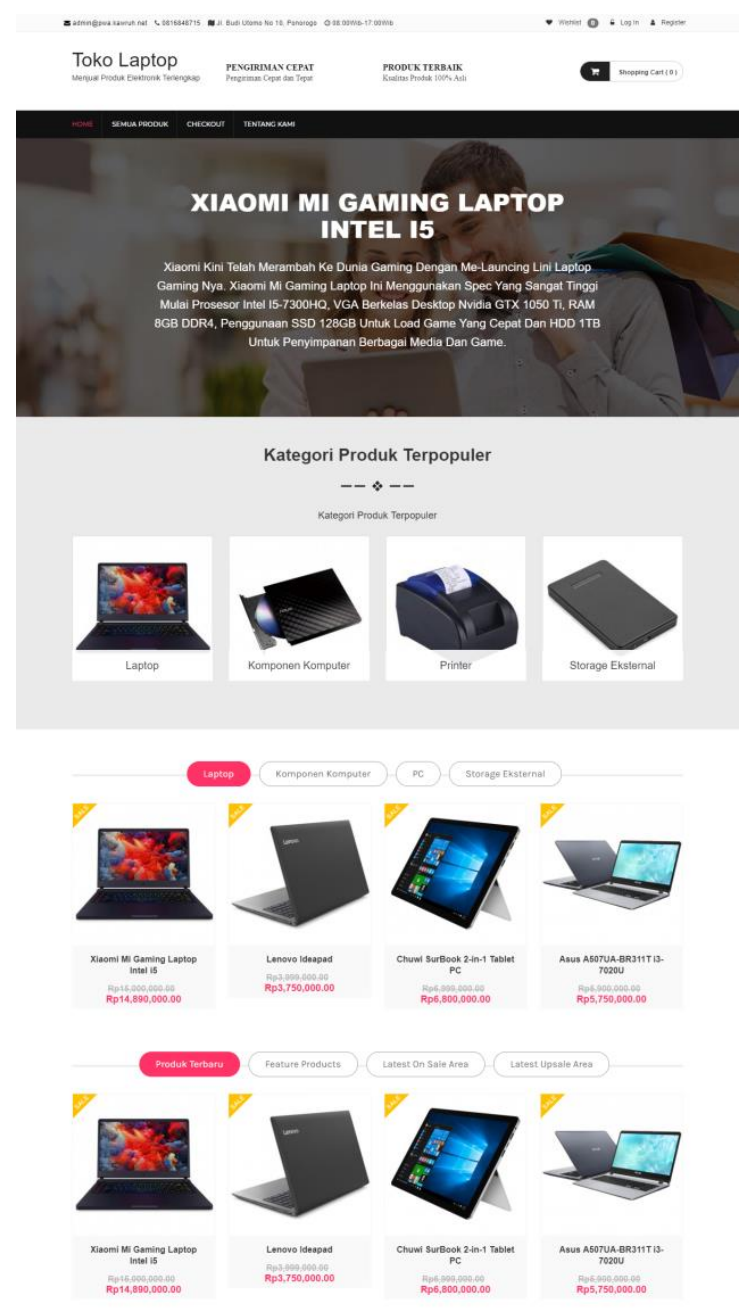

Gambar 3 Tampilan E-Commerce pada Browser Desktop 


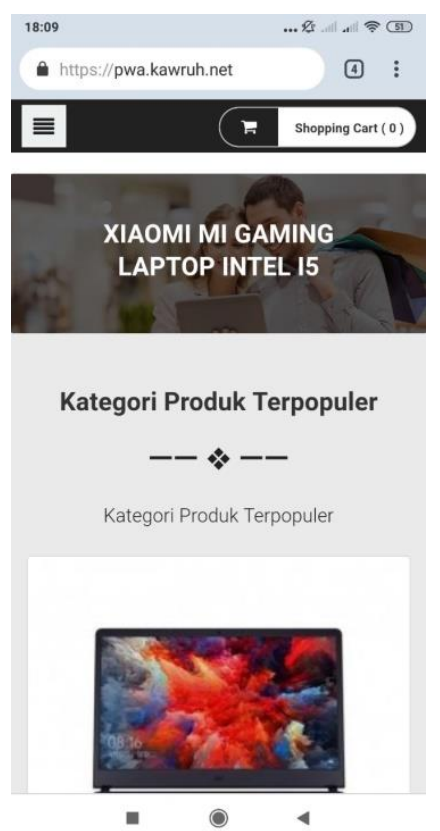

Gambar 4 Tampilan E-Commerce pada Browser Mobile

Dengan menggunakan responsive theme tampilan e-commerce dapat menyesuaikan ukuran layar pada browser mobile yang ukuran layarnya lebih kecil dibandingkan PC/Laptop. 3.2. Menerapkan PWA pada E-commerce

Langkah pertama yang dilakukan untuk menerapkan PWA pada e-commerce adalah mengambil JSON pada halaman Home yang menampilkan semua data produk dan kategori produk.

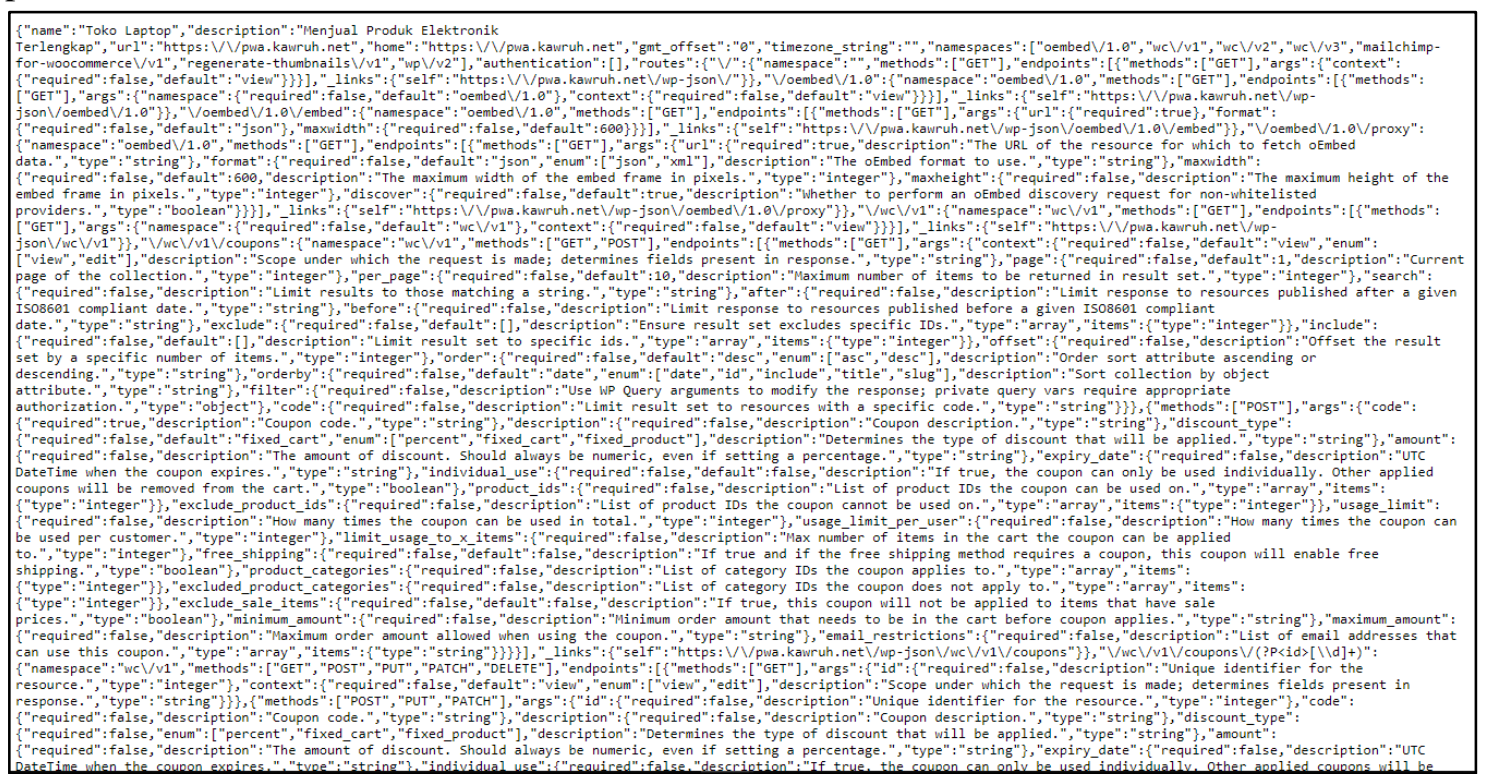

Gambar 5 Potongan JSON Halaman Home

Setelah JSON halaman Home berhasil didapat, langkah selanjutnya adalah menyisipkan service worker. Service worker adalah tool yang sangat kuat pada PWA yang menyediakan fungsionalitas offline, push notification, pembaruan konten, caching konten, dan banyak lagi lainnya [6]. 


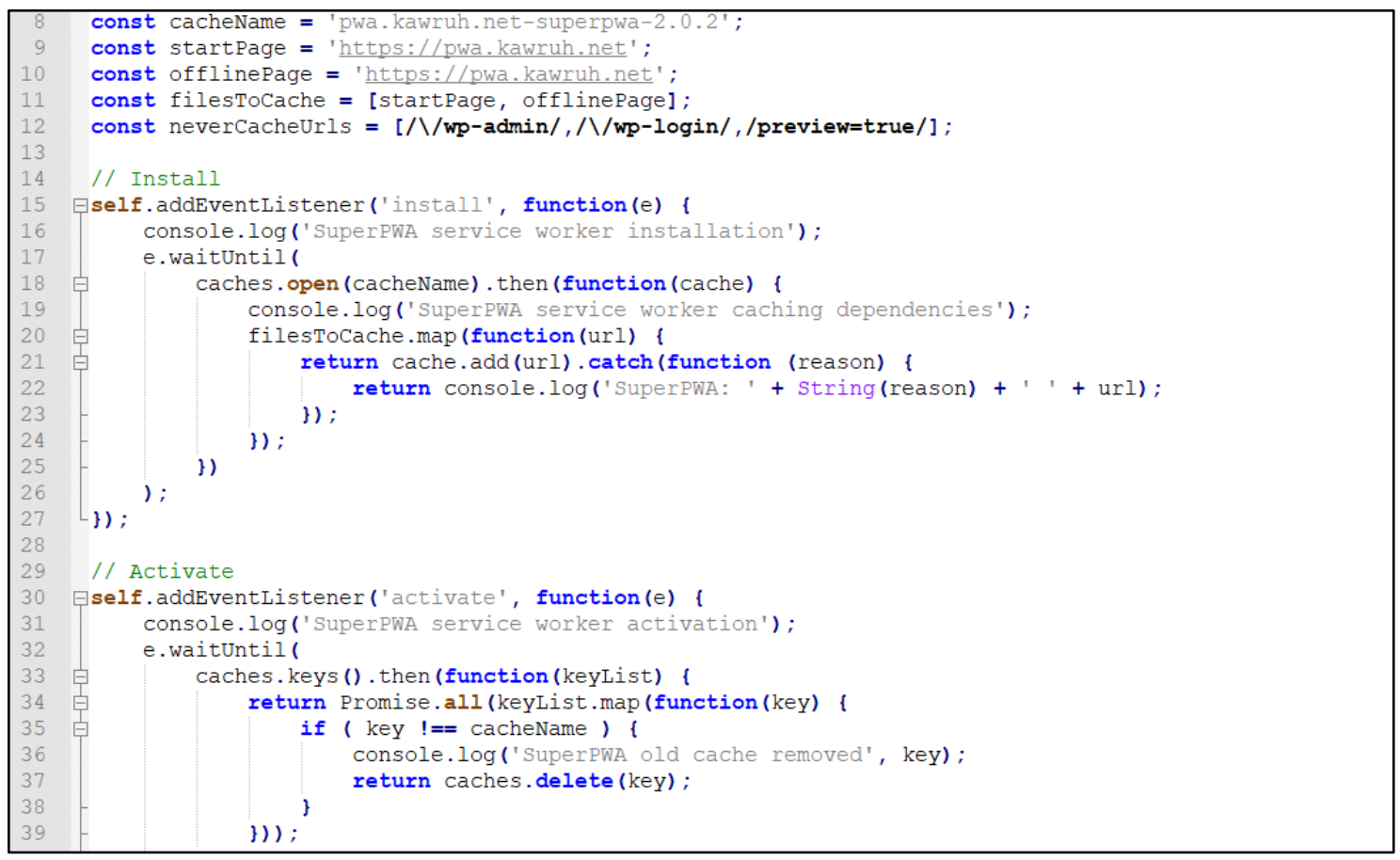

Gambar 6 Potongan Source Code Service Worker

Dengan service worker memungkinkan e-commerce dapat diakses secara offline atau tanpa akses internet. Akan tetapi, service worker akan berjalan pada offline jika sebelumnya $e$ commerce sudah dijalankan pada kondisi online untuk request JSON dan melakukan caching file dengan menyimpan data-data pada halaman Home seperti data produk dan kategori produk.

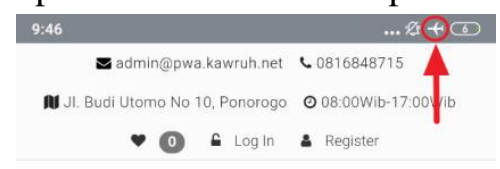

Toko Laptop

Menjual Produk Elektronik Terlengkap

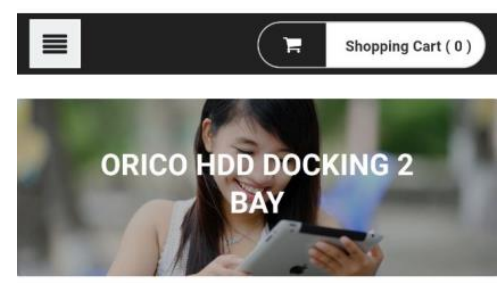

Kategori Produk Terpopuler

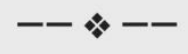

Kategori Produk Terpopuler

Gambar 7 Penerapan Service Worker pada E-Commerce pada Airplane Mode (Offline) 
Terakhir adalah membuat manifest aplikasi dalam bentuk JSON. Manifest aplikasi digunakan untuk mengatur name, short name, description, icons, background color, theme color dan orientation aplikasi pada smartphone. Selain itu, manifest aplikasi memiliki kemampuan untuk menyimpan bookmark situs ke home screen pada smartphone. [6]

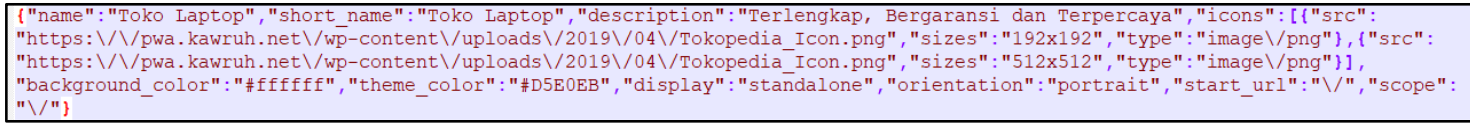
Gambar 8 Web App Manifest

Dengan menerapkan web app manifest pada e-commerce memungkinkan pengguna menambahkan aplikasi e-commerce ke layar utama smartphone atau dengan kata lain $e$ commerce dapat diinstal dalam versi mobile sehingga pengguna tidak perlu membuka browser dan mengetikkan $U R L$ untuk menjalankan aplikasi e-commerce tetapi cukup dengan mengklik ikon aplikasi e-commerce yang sudah diinstal.
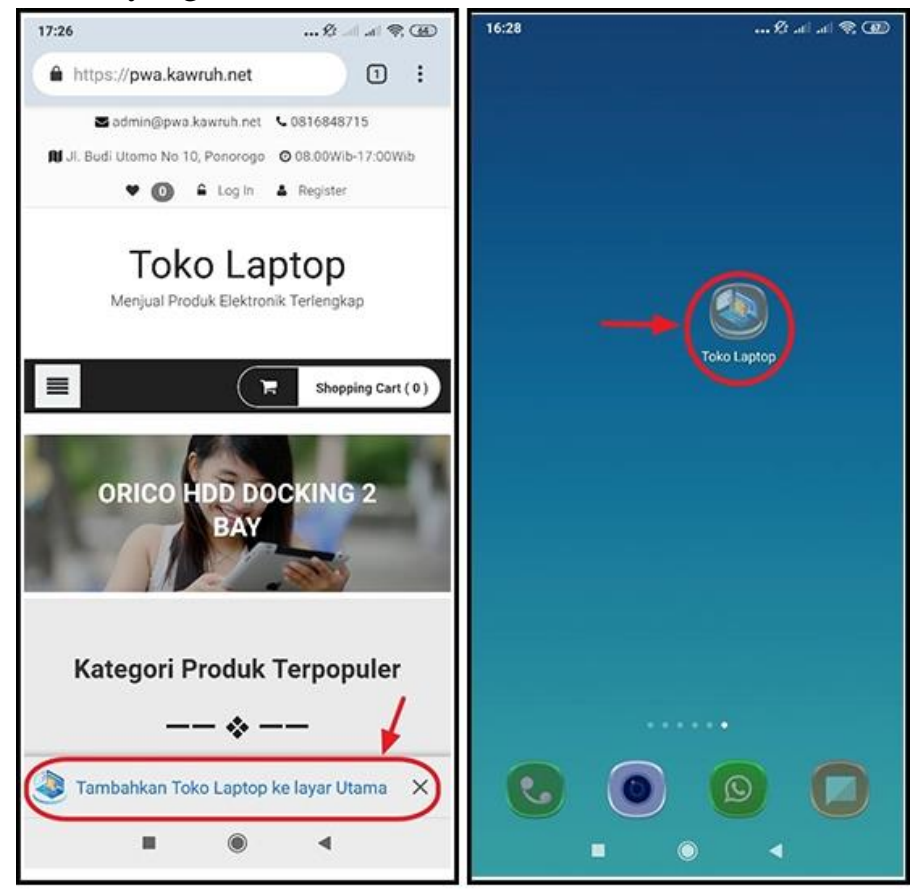

Gambar 9 Penerapan Web App Manifest untuk "Tambahkan ke Layar Utama” pada E-commerce

Selain itu, dengan manifest aplikasi kita bisa membuat splash screen dengan ikon dan nama aplikasi sesuai dengan kebutuhan. Aplikasi yang terinstal jika dijalankan tidak lagi menampilkan address bar seperti pada saat mengakses melalui browser. 


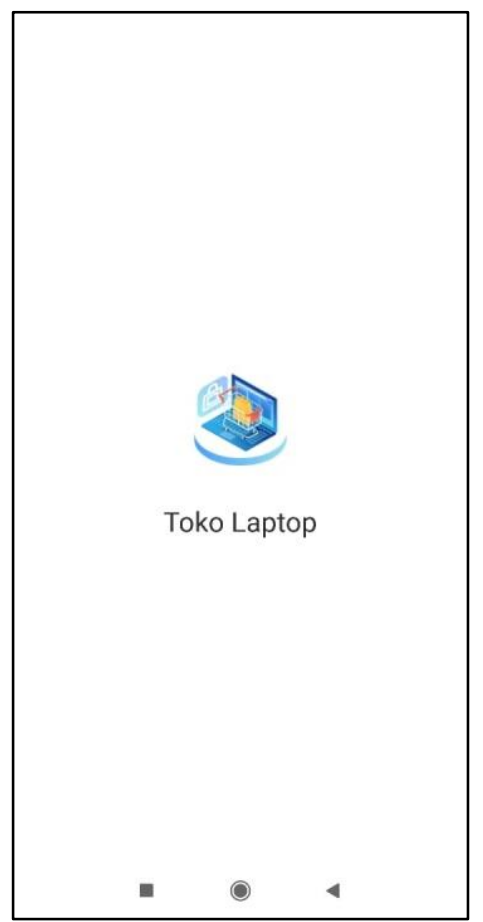

Gambar 10 Penerapan Web App Manifest untuk Splash Screen pada E-commerce

\subsection{Pengujian Aplikasi}

Pengujian PWA pada e-commerce berdasarkan baseline progressive web app checklist dilakukan dengan 2 cara yaitu menggunakan tools Lighthouse dan pengujian manual. Pengujian dengan menggunakan tools Lighthouse terdiri dari 3 kategori yaitu fast and reliable, installable dan PWA optimized dengan total 13 kriteria, sedangkan pengujian manual terdiri dari 3 kriteria. Pengujian PWA pada e-commerce disajikan pada tabel 1.

Tabel 1 Pengujian berdasarkan baseline progressive web app checklist

\begin{tabular}{|c|c|c|c|}
\hline No & Pengujian & Status & Nilai \\
\hline \multicolumn{4}{|c|}{ Pengujian dengan menggunaka tools Lighthouse } \\
\hline \multicolumn{4}{|c|}{ Fast and Reliable } \\
\hline 1 & Memuat halaman cukup cepat di jaringan seluler & Passed & 6,25 \\
\hline 2 & Current Page merespon dengan 200 ketika offline & Passed & 6,25 \\
\hline 3 & start_url merespon dengan 200 ketika offline & Passed & 6,25 \\
\hline \multicolumn{4}{|c|}{ Installable } \\
\hline 4 & Menggunakan HTTPS & Passed & 6,25 \\
\hline 5 & $\begin{array}{l}\text { Mendaftarkan service worker yang mengontrol halaman dan } \\
\text { start_url }\end{array}$ & Passed & 6,25 \\
\hline 6 & Web app manifest memenuhi persyaratan pemasangan & Passed & 6,25 \\
\hline \multicolumn{4}{|c|}{ PWA Optimized } \\
\hline 7 & Redirects HTTP traffic to HTTPS & Passed & 6,25 \\
\hline 8 & Konfigurasi untuk splash screen kustom & Passed & 6,25 \\
\hline 9 & Mengatur warna tema address-bar & Passed & 6,25 \\
\hline 10 & Konten berukuran dengan benar untuk viewport & Passed & 6,25 \\
\hline 11 & $\begin{array}{l}\text { Memiliki tag <meta name }=\text { "viewport" }>\text { dengan lebar atau } \\
\text { initial-scale }\end{array}$ & Passed & 6,25 \\
\hline 12 & Menampilkan konten ketika javascript tidak tersedia & Passed & 6,25 \\
\hline 13 & Menyediakan apple-touch-icon yang valid & Passed & 6,25 \\
\hline \multicolumn{4}{|c|}{ Pengujian Manual } \\
\hline 14 & $\begin{array}{l}\text { Situs berfungsi lintas browser (Chrome, Edge, Firefox and } \\
\text { Safari) }\end{array}$ & Passed & 6,25 \\
\hline 15 & Transisi halaman tidak terasa seperti diblokir di jaringan & Passed & 6,25 \\
\hline 16 & Setiap halaman memiliki URL & Failed & 0 \\
\hline \multicolumn{3}{|c|}{ Total } & 93,75 \\
\hline
\end{tabular}


Berdasarkan pengujian yang ditampilkan pada tabel 1 di atas dapat dilihat bahwa $e$ commerce memiliki nilai kualitas PWA yang cukup baik yaitu 93,75 dari 100 nilai maksimal.

\section{KESIMPULAN}

Dengan menerapkan web app manifest pada PWA, pengguna dapat menjalankan aplikasi e-commerce layaknya aplikasi native yang dapat dijalankan dengan mengklik ikon pada layar utama smartphone. E-commerce juga dapat diakses pada berbagai platform dengan menggunakan browser seluler maupun desktop pada keadaan offline dengan disisipkannya service worker, sehingga pengguna dapat mengakses e-commerce tanpa jaringan internet. Akan tetapi tidak semua halaman atau fitur dapat diakses secara offline.

Pengujian yang dilakukan berdasarkan baseline progressive web app checklist, nilai kualitas PWA pada e-commerce cukup baik yaitu 93,75 dari 100 nilai maksimal. Dari 16 kriteria pengujian, 15 diantaranya dapat diimpelementasikan pada e-commerce.

\section{SARAN}

Pada penelitian ini penerapan PWA untuk mode offline hanya dapat diterapkan pada satu halaman saja sehingga aplikasi bisa dijalankan tanpa jaringan internet akan tetapi aksesnya sangat terbatas, untuk saran penelitian selanjutnya untuk dapat menerapkan PWA untuk mode offline pada lebih dari satu halaman atau fitur.

\section{DAFTAR PUSTAKA}

[1] A. Mhaske, A. Bhattad, P. Khamkar, and R. More, "Progressive Web App for Educational System," Int. Res. J. Eng. Technol., pp. 310-312, 2018.

[2] P. Loreto, J. Braga, H. Peixoto, J. Machado, and A. Abelha, "Step towards progressive web development in obstetrics," Procedia Comput. Sci., vol. 141, pp. 525-530, 2018.

[3] T. A. Majchrzak, A. Biørn-Hansen, and T.-M. Grønli, "Progressive Web Apps: the Definite Approach to Cross-Platform Development?," Proc. 51st Hawaii Int. Conf. Syst. Sci., pp. 5735-5744, 2018.

[4] I. Malavolta, "Beyond native apps: web technologies to the rescue! (keynote)," pp. 1-2, 2016.

[5] S. Valente, J. Braga, J. Machado, M. Santos, and A. Abelha, "The Impact of Mobile Platforms in Obstetrics," Procedia Technol., vol. 9, pp. 1201-1208, 2014.

[6] V. Karpagam, "Performance Enhancement of Webpage Using Progressive Web App Features," Int. J. Innov. Res. Adv. Eng., vol. 03, no. 4, pp. 2349-2163, 2017.

[7] R. S. Pressman, Rekayasa Perangkat Lunak, 7th ed. Yogyakarta: Andi, 2012. 